\title{
Application of RQA and SOM for identification of two-phase flow patterns during boiling in horizontal minichannel
}

\author{
Hubert Grzybowski *, Iwona Zaborowska, and Romuald Mosdorf \\ Department of Mechanics and Applied Computer Science, Faculty of Mechanical Engineering, Bialystok University of Technology, \\ Wiejska 45 C, 15-351 Bialystok, Poland
}

\begin{abstract}
In the paper, numerical methods of data analysis recurrence quantification analysis (RQA) and self-organizing map (SOM) have been used to analyse pressure drop oscillations during the flow boiling in minichannel. The performed analysis allows us to identify flow patterns based on the character of the pressure drop oscillations. The following two-phase flow patterns have been identified: liquid flow, liquid flow with small vapour bubble, slug flow, long slug flow and confined bubble flow. In the experiment, the open-loop boiling system in a circular horizontal minichannel with an inner diameter of $1 \mathrm{~mm}$ was investigated. The two-phase flow patterns at the outlet of the heated section were observed through the glass tube (with an inner diameter of $1 \mathrm{~mm}$ ) and recorded by a high-speed camera Phantom v1610.
\end{abstract}

\section{Nomenclature}

$l \quad$ length of diagonal line

$L \max \quad$ length of the longest diagonal line

$m$ embedding dimension

$G \quad$ mass flux, $\mathrm{kg} \cdot \mathrm{m}^{-2} \cdot \mathrm{s}^{-1}$

$n \quad$ dimension of input vector

$N \quad$ number of samples

$p \quad$ pressure, $\mathrm{Pa}$

$P$ heat input, $\mathrm{W}$

$q \quad$ heat rate, $\mathrm{W}$

$\mathbf{R}$ set of real numbers

RP recurrence plot

RQA recurrence quantification analysis

SOM Kohonen self-organizing neural network

SVM support vector machine

$T$ temperature difference, $\mathrm{K}$

$t$ time, $\mathrm{s}$

$x \quad$ measured value

$w \quad$ weighting coefficient

y measured value

Greek symbols

$\varepsilon \quad$ threshold for $R P$ computation

$\Theta \quad$ Heaviside function

$\tau \quad$ time delay (samples)

Subscripts

1,2 number of channel

$i, j \quad$ indices

\section{Introduction}

The two-phase flow in small, mini and micro hydraulic diameter channels is attracting increasing attention because of the ability to dissipate high heat fluxes. Analysis reported in works [1,2] suggest that mini- and microchannels are more prone to various types of twophase flow instabilities, which in turn can cause fluctuations of pressure drop and channel temperature (periodic or non-periodic). Most research on minichannel flow boiling has focused on determining pressure drop and heat transfer correlations [3-5]. The last decade has witnessed an increase in improving the efficiency and stability of heat transfer by modifying the geometry and surface of channels [6,7], using the nanofluids [8-10], adding microencapsulated phase change materials [11]. Naga Ramesh et al. provides a detailed review of heat transfer enhancement in microchannel heat sinks [12]. The boiling behavior and flow patterns have attracted considerable attention from many researches. They mainly focuses on flow patterns classification [13-15], bubble formation [16] and mass transfer in flow boiling [17].

Many works report that different types of instabilities are superimposed on each other [18-20]. Few studies have explored pattern transition models [21] and flow regime mapping [22]. The flow patterns classification for unstable boiling has not been explored in-depth [23]. The heat transfer mechanisms are strongly related to flow pattern dynamics. Despite of large interest of flow patterns classification, only a few studies have explored the identification of flow patterns based on image $[24,25]$ or signal processing analysis [26,27]. To identify the flow patterns in air-water horizontal twophase flow the Kohonen self-organising feature map was applied in paper [28]. However, in this paper eight linear stochastic features were used to identify flow patterns for macrochannel.

The present paper combines SOM with RQA to identify flow boiling patterns in a horizontal minichannel. This identification method analyses the dynamics of the

* Corresponding author: h.grzybowski@pb.edu.pl 
pressure drop during density-wave oscillations (DWO) superimposed to the pressure-drop oscillation (PDO) cycle.

\section{Experimental setup}

The schematic diagram of the open-loop system is shown in Figure 1. The flow of distilled water (working liquid) begins in the supply tank (Figure $1-1$ ), from where it flows to the surge tank (Figure $1-3$ ) and then to the heated section. The overpressure in the surge tank was constant and equal to $50 \mathrm{kPa}$. A ball valve (Figure $1-2$ ) was used to control the liquid flow rate. The heated section consists of one brass pipe with an inner diameter of $1 \mathrm{~mm}$ and an outer diameter of $2 \mathrm{~mm}$ (Figure $1-4)$. The brass pipe was the length of $100 \mathrm{~mm}$. To the end of the brass pipe a glass tube of the same dimensions was mounted. The glass tube made it possible to observe the flow patterns formed during boiling using a highspeed camera $-1000 \mathrm{fps}$ (Figure $1-6$ ). The following flow patterns during experiment were observed: liquid flow, liquid flow with small vapour bubble, slug flow, long slug flow and confined bubble flow.

For the identification of flow patterns by RQA and SOM pressure drop. The three different sets of experimental parameters were chosen to the analysis. These operating conditions are presented in Table 1. From the examined time series, one cycle of long-term pressure drop changes were selected. Selected time series of pressure drop are shown in Figure 2.

Table 1. Mass flux and heat input for all experimental cases.

\begin{tabular}{ccc}
\hline $\begin{array}{c}\text { Case } \\
\text { Number }\end{array}$ & $\begin{array}{c}\text { Mass flux } \\
\left(\mathrm{kg} / \mathrm{m}^{2} \mathrm{~s}\right)\end{array}$ & $\begin{array}{c}\text { Heat input } \\
(\mathrm{W})\end{array}$ \\
\hline 1 & 159 & 46.3 \\
2 & 159 & 57.2 \\
3 & 24 & 40.3 \\
\hline
\end{tabular}

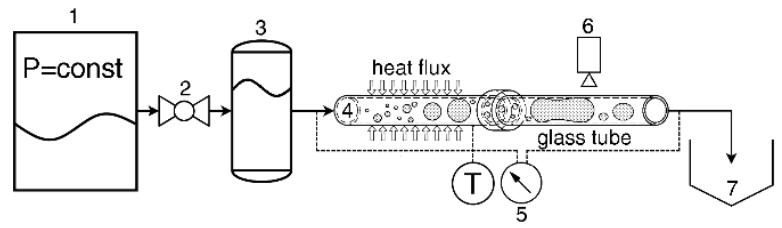

Fig. 1. Schematic diagram of experimental setup: (1) supply tank (2) ball valve (3) surge tank; (4) heated minichannel; (5) pressure drop sensor; (6) high speed camera; (7) overflow tank.

\section{Nonlinear data analysis}

A windowed RQA was used to detect changes in the dynamics of pressure drop fluctuations. The used method is based on a quantitative analysis of information contained in recurrence plots RP [29]. RP of a dynamical system is expressed by two-dimensional matrix [30]:

$$
R_{i, j}=\Theta\left(\varepsilon_{i}-\left\|x_{i}-x_{j}\right\|\right), x_{i} \in \mathbf{R}^{m}, i, j-1 \ldots N
$$

where $N$ is the number of considered states $x, \varepsilon$ is a threshold distance, \|\| is a norm in $m$-dimensional space, $\Theta$ is the Heaviside function and $\mathbf{R}$ is a set of real numbers.

To create an RP for attractor reconstruction must be estimated the following parameters: embedding dimension $(m)$, time delay $(\tau)$ and threshold distance $(\varepsilon)$. In Figure 3a the false nearest neighbour algorithm vs $m$ is presented. The correct value of parameter $m$ is when the number of false points reaches zero. To determine $\tau$ for the generated phase space, the graph of mutual information vs time delay was made in which the first minimum is the proper value of $\tau$ (Figure $3 \mathrm{~b}$ ). It was assumed that the value of $\varepsilon$ was determined by the size of the reconstructed attractor in the $m$-dimensional phase space. $10 \%$ of the attractor's maximum diameter was selected as the appropriate value of $\varepsilon$. In Figure 4 the examples of RP for pressure drop obtained for each experimental are presented.
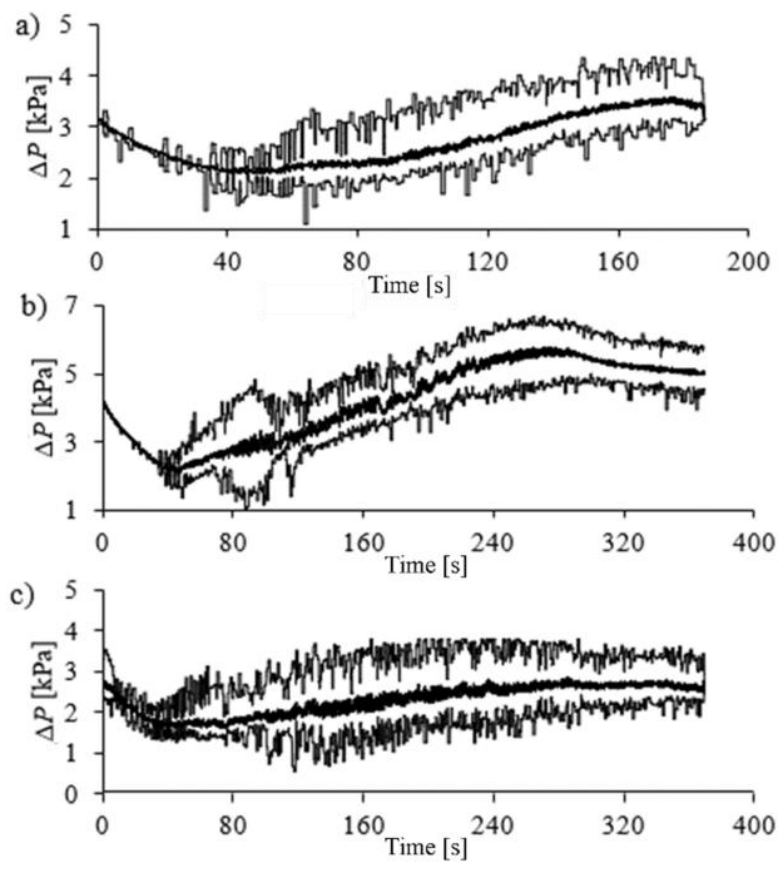

Fig. 2. Example of pressure drop oscillation for different heat input and mass flux: a) $G=159 \mathrm{~kg} / \mathrm{m}^{2} \mathrm{~s}, P=46,3 \mathrm{~W}$; b) $G=159 \mathrm{~kg} / \mathrm{m}^{2} \mathrm{~s}, P=57,2 \mathrm{~W}$; c) $G=24 \mathrm{~kg} / \mathrm{m}^{2} \mathrm{~s}, P=40,3 \mathrm{~W}$.
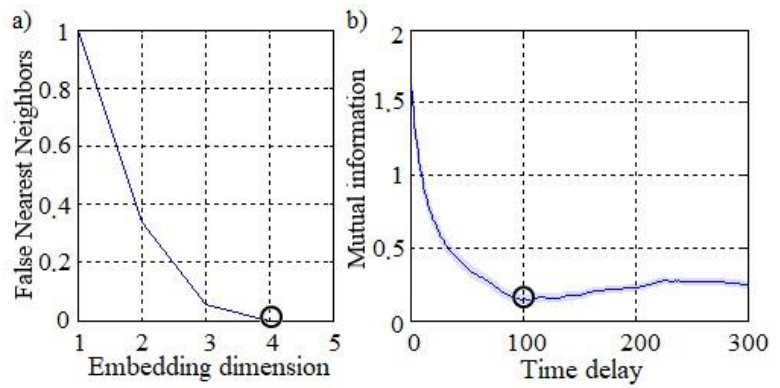

Fig. 3. The analysis of $m$ and $\tau$ for pressure drop in 101-105 s for $G=159 \mathrm{~kg} / \mathrm{m}^{2} \mathrm{~s}, P=46,3 \mathrm{~W}$ (Figure 2a): (a) false nearest neighbors as a function of the embedding dimension, (b) mutual information as a function of time delay. The calculations have been made using the CRP toolbox for Matlab® [31]. 
The values of RQA coefficients have been calculated using the CRP package implemented by Marwan and used in Matlab [31]. In the case of windowed RQA for pressure drop fluctuations, the values of $m, \tau$ and $\varepsilon$ changed over time. These values were determined for each window separately. The windowed RQA analysis for RQA coefficients and $\tau, \varepsilon$ and $\mathrm{m}$ were performed by shifting window containing 5000 samples by the step equal to 1000 samples along with the signal. In this way, the RQA coefficients and $\tau, \varepsilon$ and $m$ allowed to evaluate changes in system dynamics over time. The result of the performed analysis is a matrix for each RQA coefficients and $m, \varepsilon$ and $\tau$.
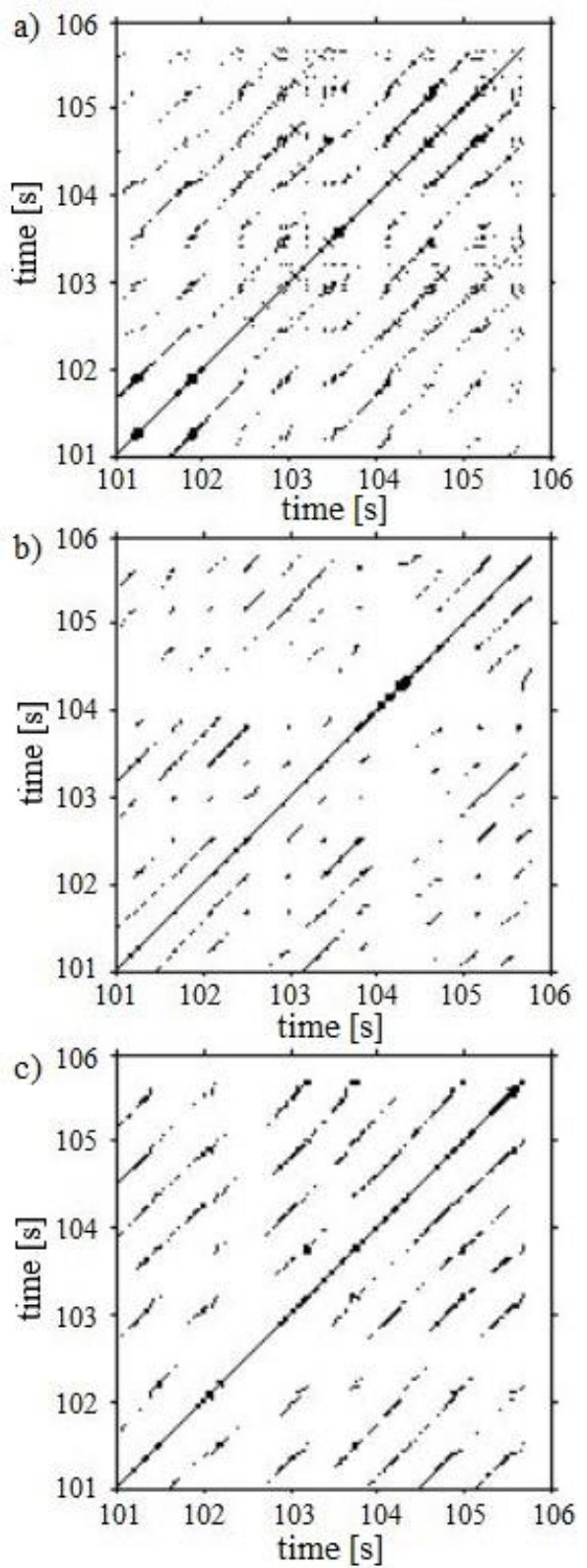

Fig. 4. Recurrence plots obtained for the analyzed pressure drop signals in the time interval from 101-106 s: a) $G=159$ $\mathrm{kg} / \mathrm{m}^{2} \mathrm{~s}, P=46.3 \mathrm{~W}$, where $m=4, \tau=100, \varepsilon=0.8$; b) $G=159$ $\mathrm{kg} / \mathrm{m}^{2} \mathrm{~s}, \mathrm{P}=57.2 \mathrm{~W}$, where $m=3, \tau=107, \varepsilon=0.54$; c) $G=24$ $\mathrm{kg} / \mathrm{m}^{2} \mathrm{~s}, \mathrm{P}=40.3 \mathrm{~W}$, where $m=4, \tau=103, \varepsilon=0.65$. The calculations have been made using the CRP toolbox for Matlab ${ }^{\circledR}[31]$.

\section{Kohonen self-organizing networks \\ neural}

The Kohonen network is an example of an unattended network. The idea of a self-organizing system appeared in the 1950s and was proposed by Finnish computer scientist Teuvo Kohonen [32]. In this algorithm, each small element (called neuron) gets many inputs and generates only one output signal. The individual input connections have an assigned weight. When a neuron receives an input pattern, it usually calculates the weighted sum of inputs. In principle, it is useful to consider the values of different weights as components of the weight vector and individual input signals as components of the input vector. Therefore, this algorithm is expressed in the following way [33]:

$$
Y=W \cdot X=\sum_{i=1}^{i=n} w_{i} \cdot x_{i}
$$

where $X$ is the input vector, $W$ is the weight vector, $n$ is the dimension of the input vector, $Y$ is the output vector.

The input vector, $X$, for SOM consists of 4 RQA coefficients, which the row number corresponds to the duration of the pressure drop. The weight vector, $W$, consists 4 weight of components, one for each RQA coefficient. In which the row number corresponds to the number of neurons in the network. In this analysis selected 36 neurons.

The structure of SOM network includes two layers. The first layer is the $X$ layer with an input RQA vectors. The second layer is a 2D matrix $(6 \times 6)$ representing neurons. Thus, each of row from $X$ vector is assigned to 1 of 36 neurons arranged in a matrix (6x6). Obtained 2D map is called the hit histogram. The hit histogram illustrates the points density on the SOM by counting how many input vectors are mapped to each SOM node.

The process of SOM involves 4 processes: initiation, competition, cooperation and adaptation. The procedure is summarized in nine steps.

I. Reading the signal recorded during the flow boiling in minichannels.

II. Division the signal into time windows consists 5000 samples.

III. Perform windowed RQA for each time window. As a results of the analysis is obtained the input vector consists of 4 RQA coefficients to the $S O M$ analysis.

IV. SOM random initialization.

V. SOM training using 1000 iterations.

VI. Comparison of each test vector with map prototypes (SOM classification).

VII. SOM analysis results - creation of the hit histogram.

VIII. Obtaining the hit histogram from 10 results of the SOM analysis.

IX. On the basis of hit histogram building history which allow us to identify which part of pressure drop is assigned to each part of hit histogram a graph of the occurrence of oscillating boiling structures was created. 


\section{Results and discussions}

In the present paper, 4 RQA coefficients, i.e. $D E T, 1 / L$, $T^{l}$ and $l / T^{2}$ were used to detect different flow patterns. The conducted analysis using SOM was carried out in Matlab Software called the Neural Network Clustering App [34]. In Figure 5 the averaged hit histograms (selforganizing map) obtained from result of 10 repetition of SOM algorithm are presented.

a)

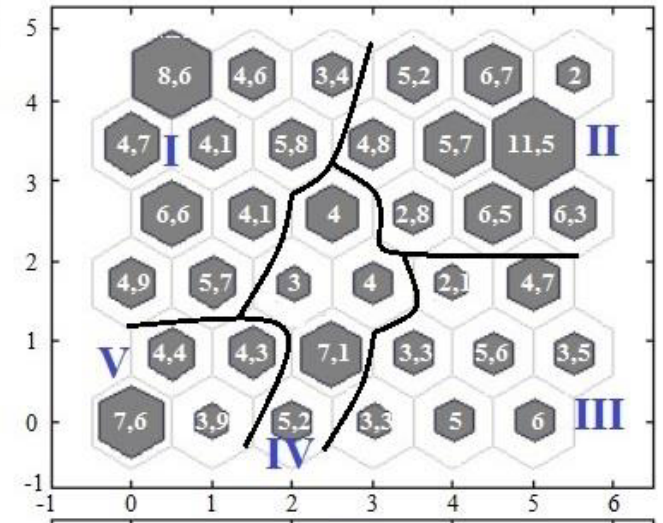

b)

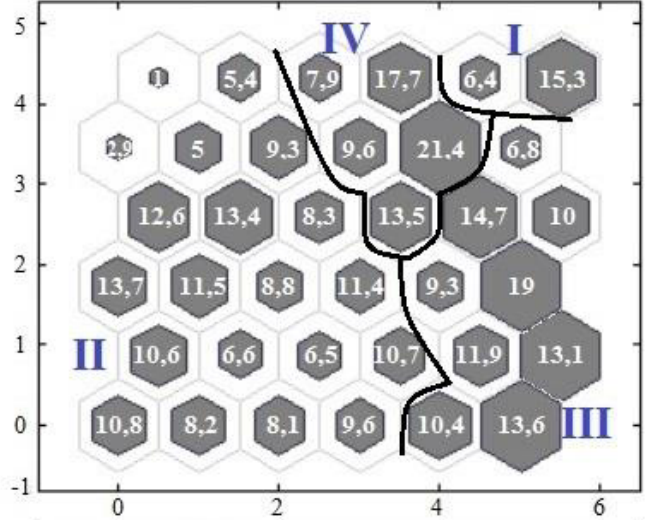

c)

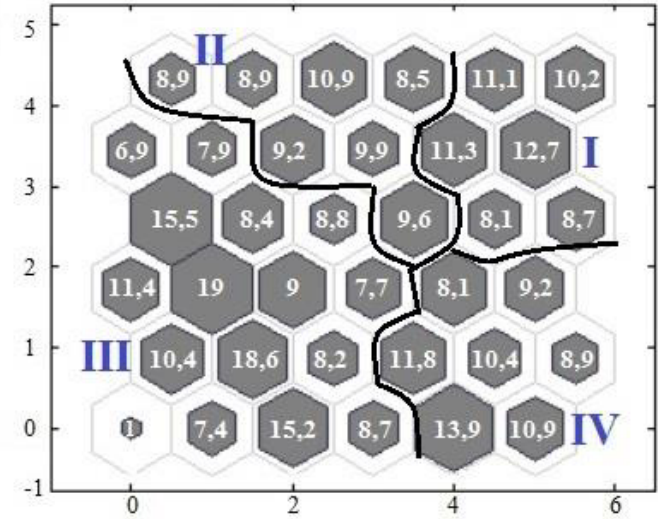

Fig. 5. Hit histograms of SOM analysis obtained for RQA coefficients: a) $G=159 \mathrm{~kg} / \mathrm{m}^{2} \mathrm{~s}, P=46,3 \mathrm{~W}$, b) $G=159$ $\mathrm{kg} / \mathrm{m}^{2} \mathrm{~s}, P=57,2 \mathrm{~W}$, c) $G=24 \mathrm{~kg} / \mathrm{m}^{2} \mathrm{~s}, P=40,3 \mathrm{~W}$

For each cases, points on the hit histogram were located according to the weight similarity of the output layer. Neurons corresponding to similar signal dynamics were located close to each other. The neurons on hit histogram have been divided according to the number of local extremes. In this way, the SOM was created using the RQA coefficients, distinguishing areas with different dynamics. Local extremes on the maps allow us to distinguish the following two-phase flow patterns:

- case of $G=159 \mathrm{~kg} / \mathrm{m}^{2} \mathrm{~s}, P=46,3 \mathrm{~W}$ : I - liquid flow, II - liquid flow with small vapour bubbles, III - long slug flow, IV - confined bubble flow, $\mathrm{V}$ - slug flow;

- case of $G=159 \mathrm{~kg} / \mathrm{m}^{2} \mathrm{~s}, P=57,2 \mathrm{~W}$ and $G=24$ $\mathrm{kg} / \mathrm{m}^{2} \mathrm{~s}, P=40,3 \mathrm{~W}$ : I - liquid flow, II - liquid flow with small vapour bubbles, III -slug flow, IV - long slug flow.

The hit histogram algorithm identifies which part of the pressure oscillation signal is assigned to each part of the map, and thus assign the selected fragment of pressure changes to the appropriate pattern. The analysis carried out in this way allows us to obtain a graph of occurrence of two-phase flow patterns during pressure oscillation.

In Figure 6, 7 and 8 the results of RQA and SOM analysis for the three cases under consideration. analysed. For each analysed data, the results were compared with the pressure drop oscillations. In Figure $6 \mathrm{a}, 7 \mathrm{a}, 8 \mathrm{a}$ a pressure drop oscillations are shown, whereas in Figure 6b, 7b, 8b graph of occurrence of twophase flow patterns in time duration of the pressure drop are presented. On the ordinate axes in Figure $6 b, 7 b, 8 b$, specific two-flow patterns are marked by the numbers. These two-flow patterns are indicated in the hit histograms in Figure 5.
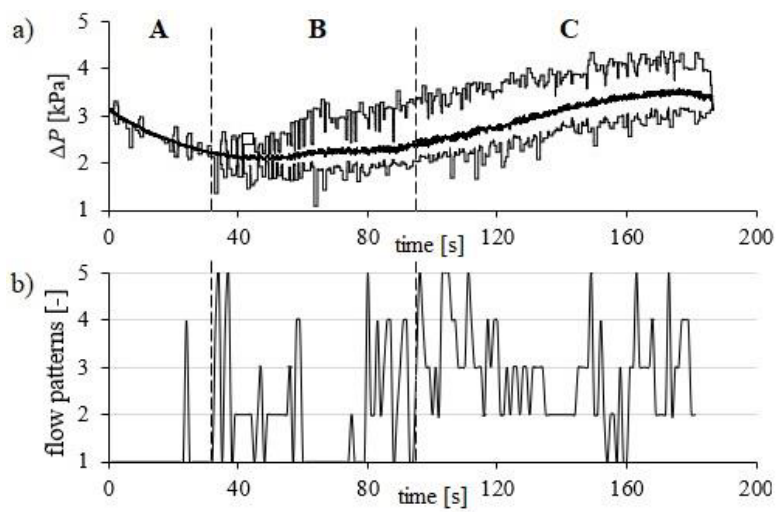

Fig. 6. The results of RQA and SOM analysis for $G=159$ $\mathrm{kg} / \mathrm{m}^{2} \mathrm{~s}, P=46,3 \mathrm{~W}$ : (a) pressure drop, (b) graph of occurrence of two-phase flow patterns in time duration of the pressure drop.
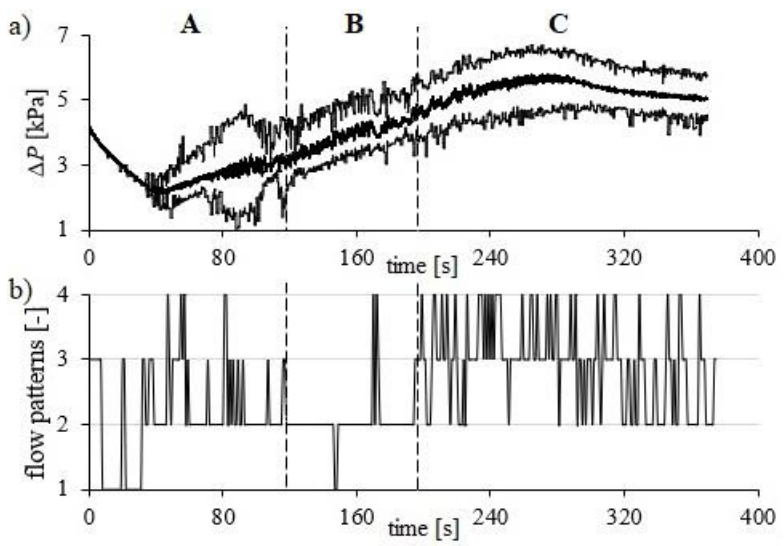

Fig. 7. The results of RQA and SOM analysis for $G=159$ $\mathrm{kg} / \mathrm{m}^{2} \mathrm{~s}, P=57,2 \mathrm{~W}$ : (a) pressure drop, (b) graph of occurrence of two-phase flow patterns in time duration of the pressure drop. 


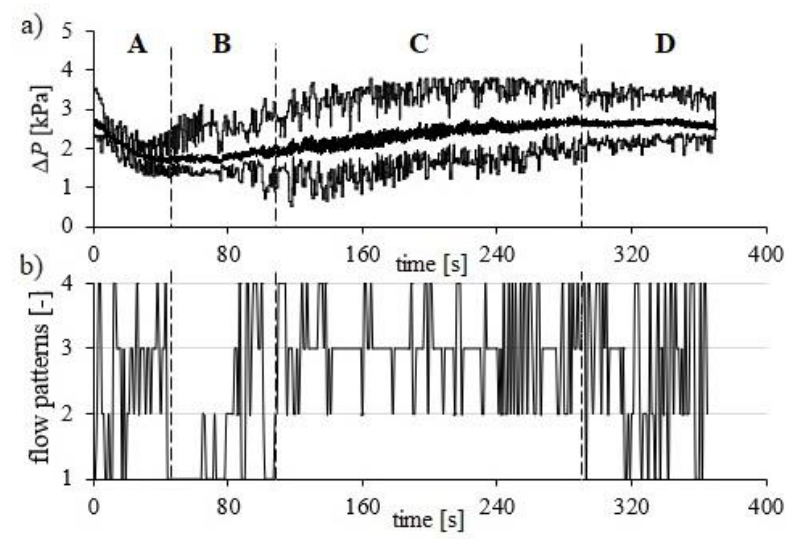

Fig. 8. The results of RQA and SOM analysis for $G=24$ $\mathrm{kg} / \mathrm{m}^{2} \mathrm{~s}, P=40,3 \mathrm{~W}$ : (a) pressure drop, (b) graph of occurrence of two-phase flow patterns in time duration of the pressure drop.

\section{Conclusion}

For each case under consideration, different areas with different boiling dynamics were distinguished, which are marked with A, B, C and D letters in Figure 6, 7 and 8 . These areas are characterized by different boiling intensity. In Figure 6 and 7, 8 areas with different boiling dynamics were distinguished. For experimental dataset with a lower mass flux (Figure 8), 4 areas with different boiling dynamics were distinguished. The occurrence of an additional area D (Figure 8) is associated with an increase in boiling intensity. The length of each of these areas is different. In addition, each of these areas has different boiling patters. Each of area (A, B, C, D - Figure 6, 7 and 8) shows a different ways of oscillations of two-phase flow patterns, also the duration of two-phase flow patterns are changing. However, in each identified areas we can distinguish dominant flow pattern. For example in area $\mathrm{A}$ in Figure 6 the dominant flow pattern is a liquid flow, which is interrupted by a confined bubble flow. This situation was also noticed in the paper [35] where the occurrence of a dominant sequence of flow pattern changes was called a temporary boiling pattern.

The accuracy of SOM analysis is primarily related to the length of the time window in the windowed RQA. Thus, in our analysis the two-phase flow patterns which occurs more than $5 \mathrm{~s}$ cannot be identified.

Moreover, the accuracy of the identification of boiling patterns by means of the SOM analysis is related to the non-universality of the classification by means of the SOM map. However, the obtained results can be considered as sufficient for the flow pattern identification.

\section{Acknowledgments}

Project financing through the program of the Minister of Science and Higher Education of Poland named "Regional Initiative of Excellence" in $2019-2022$ project number 011/RID/2018/19 amount of financing 12,000,000 PLN

\section{References}

1. L. C. Ruspini, C. P. Marcel, and A. Clausse, International Journal of Heat and Mass Transfer 71, 521 (2014)

2. Y. K. Prajapati and P. Bhandari, Experimental Thermal and Fluid Science 88, 576 (2017)

3. P. S. Lee, S. V. Garimella, and D. Liu, Int. J. Heat Mass Transf. 48, 1688 (2005)

4. L. Sun and K. Mishima, Int. J. Multiph. Flow 35, 47 (2009)

5. G. Hetsroni, A. Mosyak, E. Pogrebnyak, and L. P. Yarin, Int. J. Heat Mass Transf. 48, 5580 (2005)

6. M. Piasecka, K. Strąk, and B. Maciejewska, International Journal of Multiphase Flow 137, 103559 (2021)

7. H. Bazdar, D. Toghraie, F. Pourfattah, O. A. Akbari, H. M. Nguyen, and A. Asadi, J. Therm. Anal. Calorim. 139, 2365 (2020)

8. R. Chein and J. Chuang, Int. J. Therm. Sci. 46, 57 (2007)

9. N. Pahlevaninejad, M. Rahimi, and M. Gorzin, J. Therm. Anal. Calorim. 143, 811 (2021)

10. L. Lin, J. Zhao, G. Lu, X.-D. Wang, and W.-M. Yan, International Journal of Thermal Sciences 118, 423 (2017)

11. C. J. Ho, Y.-H. Chiou, W.-M. Yan, and M. Ghalambaz, International Journal of Mechanical Sciences 151, 95 (2019)

12. K. N. Ramesh, T. K. Sharma, and G. A. P. Rao, Archives of Computational Methods in Engineering (2020)

13. E. A. Chinnov, F. V. Ron'shin, and O. A. Kabov, Thermophysics and Aeromechanics 22, 265 (2015)

14. J. Qian, X. Li, Z. Wu, Z. Jin, and B. Sunden, Microfluid. Nanofluid. 23, 116 (2019)

15. G. Rafalko, I. Zaborowska, H. Grzybowski, and R. Mosdorf, ENERGIES 13, (2020)

16. T. Fu and Y. Ma, Chemical Engineering Science 135, 343 (2015)

17. M. N. Kashid, A. Renken, and L. Kiwi-Minsker, Industrial and Engineering Chemistry Research 50, 6906 (2011)

18. M. M. Padki, H. T. Liu, and S. Kakac, International Journal of Heat and Fluid Flow 12, 240 (1991)

19. H. T. Liu and S. Kakac, Wärme- Und Stoffübertragung 26, 365 (1991)

20. Ö. Çomakl1, S. Karslı, and M. Yılmaz, Energy Conversion and Management 43, 249 (2002)

21. M. M. Mahmoud and T. G. Karayiannis, Experimental Thermal and Fluid Science 70, 270 (2016)

22. T. Harirchian and S. V. Garimella, International Journal of Heat and Mass Transfer 53, 2694 (2010)

23. T. G. Karayiannis and M. M. Mahmoud, Applied Thermal Engineering 115, 1372 (2017)

24. M. S. G. Nandagopal, E. Abraham, and N. Selvaraju, Chemical Engineering Journal 309, 850 (2017) 
25. J. Xiao, X. Luo, Z. Feng, and J. Zhang, AIP Advances 8, 015123 (2018)

26. R. Mosdorf and G. Górski, International Communications in Heat and Mass Transfer 64, 14 (2015)

27. N. D. Jin, X. B. Nie, Y. Y. Ren, and X. B. Liu, Flow Measurement and Instrumentation 14, 169 (2003)

28. S. Cai, H. Toral, J. Qiu, and J. S. Archer, The Canadian Journal of Chemical Engineering 72, 440 (1994)

29. N. Marwan, M. Carmen Romano, M. Thiel, and J. Kurths, Physics Reports 438, 237 (2007)

30. J.-P. Eckmann, S. O. Kamphorst, and D. Ruelle, EPL 4, 973 (1987)

31. N. Marwan, ,Cross Recurrence Plot Toolbox for MATLAB ${ }$, Ver. 5.22 (R32.6), http://tocsy.pik-potsdam.de/CRPtoolbox/, Accessed 2021-08-02."

32. T. Kohonen, Biol. Cybern. 43, 59 (1982)

33. S. Cai, H. Toral, J. Qiu, and J. S. Archer, The Canadian Journal of Chemical Engineering 72, 440 (1994)

34. L. Abell, Neural Network and Applications Using Matlab: Fit Data, Classify Patterns, Cluster Data and Time Series, CreateSpace Independent Publishing Platform, North Charleston, SC, USA, (2017)

35. H. Grzybowski and R. Mosdorf, International Communications in Heat and Mass Transfer 95, 25 (2018) 